\title{
Assemblages of anoxygenic phototrophic bacteria in tank bromeliads exhibit a host-specific signature
}

\author{
Antoine Vergne $^{1}$ | Vincent Darbot ${ }^{1}$ | Corinne Bardot ${ }^{1}$ | François Enault ${ }^{1}$ | \\ Anne-Hélène Le Jeune $^{1}$ | Jean-François Carrias ${ }^{1}$ (D) | Bruno Corbara ${ }^{1}$ (D) | \\ Régis Céréghino $^{2}$ (D) | Céline Leroy ${ }^{3,4}$ (D) | Christian Jeanthon ${ }^{5}$ | Eric Giraud ${ }^{6}$ | \\ Isabelle Mary ${ }^{1}$ | Anne-Catherine Lehours ${ }^{1}$
}

\footnotetext{
${ }^{1}$ Laboratoire Microorganismes: Génome et Environnement, Université Clermont Auvergne, CNRS, Clermont-Ferrand, France; ${ }^{2}$ Laboratoire Ecologie Fonctionnelle et Environnement, Université de Toulouse, CNRS, INPT, UPS, Toulouse, France; ${ }^{3}$ AMAP, University of Montpellier, CIRAD, CNRS, INRAE, IRD, Montpellier, France; ${ }^{4}$ UMR EcoFoG, CNRS, CIRAD, INRAE, AgroParisTech, Université des Antilles, Université de Guyane, Kourou, France; ${ }^{5} \mathrm{CNRS}$, Sorbonne Université, Station Biologique de Roscoff, Adaptation et Diversité en Milieu Marin, Roscoff, France and ${ }^{6}$ IRD, Laboratoire des Symbioses Tropicales et Méditerranéennes (LSTM), UMR IRD/SupAgro/INRA/Université de Montpellier/CIRAD, Montpellier Cedex 5, France
}

Correspondence

Anne-Catherine Lehours

Email: a-catherine.lehours@uca.fr

\section{Funding information}

Fondation pour la Recherche sur la Biodiversite; Investissement d'Avenir grant ((Labex CEBA), Grant/Award Number: ANR10-LABX-25-01; Fédération des Recherches en Environnement (FR Environnement, UCA/CNRS FR 3467/INRAE)

Handling Editor: Ana Pineda

\section{Abstract}

1. Anoxygenic phototrophic bacteria (APB) are a very significant metabolic functional group in the phytotelmata of tank-forming Bromeliaceae plants. Considering the close relationships existing between the bromeliad and its tank microbiota, the dominance of APB raises the question of their role in the ecology and evolution of these plants.

2. Here, using pufM gene sequencing for taxonomic profiling, we investigated the structure of APB communities in the tanks of five bromeliad species exhibiting different habitat characteristics (i.e. physicochemical factors associated with the host), and occurring in different localities of French Guiana.

3. We found that APB assemblages were specific to plant species and were less dependent on location or on bromeliad habitat characteristics. This convergence suggests that the identity of the bromeliad species per se is more important than habitat filtering or dispersal to control specific assembly rules for APB.

4. The pufM OTUs were affiliated with five orders of Alpha- and Beta-proteobacteria (Rhodobacterales, Sphingomonadales, Rhizobiales, Burkholderiales and Rhodospirillales), and we assume that they may be major components of the core microbiota of plant-held waters.

5. Our findings also revealed that up to $79 \%$ of the sequences were affiliated with APB clades possessing nitrogen-fixing genes suggesting that this metabolic capability is widespread within the APB community inhabiting tank bromeliads. We hypothesized that bromeliads may benefit nutritionally from associations with free-living APB capable to fix atmospheric nitrogen.

6. Synthesis. Understanding the dominance of APB in tank bromeliads and determining whether a potential interplay exists between these partners is an intriguing 
aspect of possible mutualistic and coevolving interactions between the two existing forms of chlorophototrophy (i.e. bacteriochlorophyll-based anoxygenic and chlorophyll-based oxygenic phototrophy). In the present study, we found that bromeliad species was the main factor that explained variance in APB community composition. These findings suggest that APB and tank bromeliads may have a close, mutualistic relationship and we hypothesize according to our genomic analyses that APB may promote the bromeliad growth by provisioning essential nutrients like nitrogen.

\section{KEYWORDS}

Illumina sequencing, nitrogen fixation, phylogenetic analyses, plant-bacteria interactions

\section{1 | INTRODUCTION}

Persistent colonization of plants by various non-pathogenic microbes is an ubiquitous phenomenon which has had a pervasive impact on their evolutionary diversification (Partida-Martínez \& Heil, 2011). The microbiota allows plant hosts to gain access to complex metabolic capabilities that they inherently lack, shaping their adaptation to different habitats and lifestyles (Douglas, 2014). All plant compartments may virtually be colonized by associated microbes, the best-known ones being the apoplastic spaces (i.e. endosphere) and the plant surface areas (i.e. rhizosphere and phyllosphere). However, some plants also form supplemental habitats that host microbes, such as phytotelmata. These water bodies, held and enclosed by living plants, occur in a very wide range of ecosystems, but it is in tropical rainforests that phytotelmata display their full range and ubiquity (Kitching, 2001). A major class of these phytotelmata are tank-forming bromeliads, widely distributed vascular plants across the Neotropics (Butcher \& Gouda, 2020). Their leaves arranged in rosettes have overlapping bases, forming a tank that efficiently collects rainwater, wind-borne particles and leaf litter (Benzing, 2000). The formation of water tanks and the epiphytic life strategy are some of the key evolutionary innovations contributing to the ecological success of many bromeliad species (Benzing, 2000).

In these unique aquatic microcosms, the habitat heterogeneity and the impounded material (carbon-based leaf litter, animal carcasses and faeces) support a plethora of prokaryotic residents representing a crucial link between the plant and its surrounding environment (e.g. Brandt et al., 2017; Brouard et al., 2011; Pittl et al., 2010). This microbiota plays a pivotal role in the ecological success of tank bromeliads as many species significantly rely on the products of the microbial activities taking place in their catchments for their nutrient uptake (Benzing \& Renfrow, 1974; Endres \& Mercier, 2003; Romero et al., 2006). These resident microorganisms exhibit a rich repertoire of metabolic functions and are engaged in ecosystem processes including active nitrogen fixation, fermentation, photosynthesis or even different terminal electron accepting processes (e.g. Louca et al., 2017). Surprising and of particular interest is that anoxygenic phototrophy is a widespread and highly significant microbial metabolism in these aquatic ecosystems (e.g. Lehours et al., 2016; Louca et al., 2017). This metabolic activity is the prerogative of anoxygenic phototrophic bacteria (APB), a functional group found across six bacterial phyla (Koblížek, 2015). Besides their unifying property to perform light-dependent and bacteriochlorophyll (BChl)-mediated energy transduction, the metabolic and physiological capabilities of APB show a great diversity, ranging from aerobic photoheterotrophic to anaerobic photoautotrophic growth modes (Imhoff, 2006). Despite the diversity of their lifestyles, enabling APB to occupy a broad range of environmental conditions, their contribution to the global carbon and energy flows in marine and inland waters is often very limited compared to that of oxygenic photosynthesis (e.g. Fauteux et al., 2015; Goericke, 2002). In this context, the water found within tank bromeliads has unusual features. In these aquatic systems, the abundances of genetic markers associated with anoxygenic phototrophy revealed that the APB largely outnumbered oxygenic photoautotrophs and have a relative abundance $>20 \%$ to the global prokaryotic community (Lehours et al., 2016; Louca et al., 2017). This proportion of APB, particularly the photoheterotrophic ones, is significantly higher than in other marine and freshwater systems (Koblížek, 2015). Concurrently with these observations, very unusual high concentrations of $\mathrm{BChl}$ and of $\mathrm{BChl} /(\mathrm{BChl}+\mathrm{Chlorophyll})$ ratios have been reported (Lehours et al., 2016). These findings challenge the conventional view that this type of photochemical reaction, without oxygen production, is a negligible type of phototrophy in the ecosystems of today's biosphere (e.g. Fauteux et al., 2015; Goericke, 2002). Beyond, as the microbial biodiversity is a trait forming part of the extended phenotype of the host plant (Agler et al., 2016; Whitham et al., 2003), the preeminence of APB, in water tanks of Bromeliaceae, may have obvious implications for the understanding of the ecology and evolution patterns of these plant ponds. Besides, these possible connections open new avenue to understand the evolution of life-history traits in plants as APB were also shown to inhabit the phyllosphere of many terrestrial plants (Atamna-Ismaeel et al., 2012; Giraud et al., 2000).

In this study, we hypothesized that bromeliad species determine the APB assemblages inhabiting their water tanks because close relationships may exist between the two forms of chlorophototrophy 
(i.e. the $\mathrm{BChl}$-based anoxygenic and the Chlorophyll-based oxygenic phototrophy) into these phytotelmata. For example, tank bromeliads may provide specific habitats to APB communities and, in turn, APB may influence plant fitness through nitrogen fixation, a metabolic capability shared by some APB (e.g. Giraud et al., 2000). To disentangle whether plant identity (a) overrides the effect of stochastic processes and of forest habitat type and (b) structures the APB microbiota, we examined potential associations of bromeliad hosts with the APB assemblages. We characterized the variability of APB in terms of community structure and taxonomic composition, through analyses of the polymorphism of the pufM gene, which encodes a protein in the light reaction centre of APB (Imhoff et al., 2018). To assess the generality of our findings, we considered several individual plants from five different species of tank-forming bromeliads sampled at different localities in French Guiana and exhibiting different characteristics in their water tanks. Whereas our investigations focused primarily on the APB microbiota of tank bromeliads and to have an outgroup to the bromeliads, we addressed, to a lesser extent, the occurrence and composition of APB into axil water collected by bracts of Heliconia sp. Finally, we performed genomic analyses to further investigate whether the identified APB microbiota may have the potential for nitrogen fixation.

\section{MATERIALS AND METHODS}

\subsection{Location of sampled sites and brief description of plants}

All the samples were collected in French Guiana (Figure 1A) from October 2008 to March 2011. The climate of French Guiana is
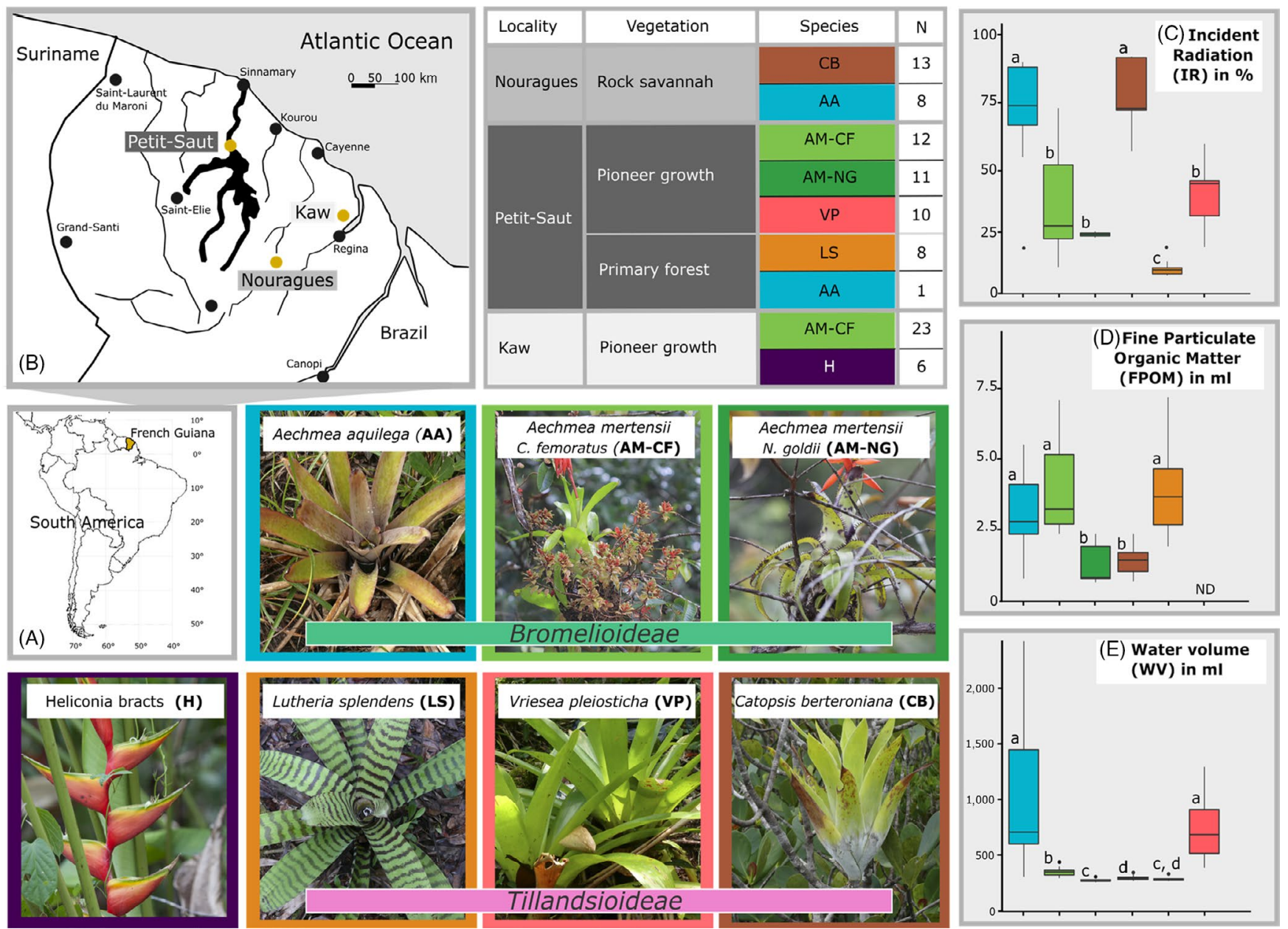

FIGURE 1 (A) Localization of French Guiana in South America and (B) distribution of sampling localities (Nouragues, Kaw, Petit-Saut) in French Guiana. The table presents the main characteristics of the sampling sites and plants sampled (six Bromeliaceae species and one Heliconia species). N: number of individuals sampled per plant species. Photographs of Aechmea aquilega (AA), Aechmea mertensii associated with the ants Camponotus femoratus (AM-CF) or Neoponera goeldii (AM-NG), Catopsis berteroniana (CB); Vriesea pleiosticha (VP); Lutheria splendens (LS); Heliconia bracts (H). AA, AM-CF and AM-NG belong to the Bromelioideae subfamily, whereas VP, LS and CB belong to the Tillandsioideae subfamily. (C-E) Boxplots displaying for each bromeliad species, (C) the percentage of incident radiations (IR, \%), (D) the volume of fine particulate organic matter recorded after decantation in test tubes (FPOM, $\mathrm{ml}$ ) and (E) the water volume extracted (WV, $\mathrm{ml}$ ). Boxes are 25 and 75 percentiles with median value. Bars represent minimum and maximum limits. Dots are extreme values. Significant differences (Wilcoxon test, $p<0.001$ ) were indicated. The colour code identifies each bromeliad species, as listed in the table provided within this figure. ND: not determined 
tropical moist with $3,000-3,400 \mathrm{~mm}$ of annual precipitation mainly distributed over 280 days. There is a significant decrease in rainfall between September and November (dry season) and another shorter and more irregular dry period in March. The maximum monthly temperatures average $33.5^{\circ} \mathrm{C}$ and the monthly minimum is $20.3^{\circ} \mathrm{C}$.

Samples from three distinct geographical areas were analysed: the Nouragues Natural Reserve $\left(04^{\circ} 05^{\prime} 16.4^{\prime \prime} \mathrm{N}, 52^{\circ} 40^{\prime} 49.3^{\prime \prime} \mathrm{W}\right)$, the forest edges around the field station at Petit-Saut, Sinnamary $\left(05^{\circ} 03^{\prime} 30.0^{\prime \prime} \mathrm{N}, 52^{\circ} 58^{\prime} 34.6^{\prime \prime} \mathrm{W}\right)$ and the Kaw mountain $\left(4^{\circ} 30^{\prime} 52^{\prime \prime} \mathrm{N}\right.$; $52^{\circ} 03^{\prime} 58^{\prime \prime} \mathrm{W}$; Figure 1B). Further descriptions of these localities can be found in Brouard et al. (2012); Bongers et al. (2001) and Céréghino et al. (2011). A total of 92 samples (86 from five tank-bromeliad species (Bromeliaceae) and 6 from one Heliconia species (Heliconiaceae), Figure 1) were recovered in the understorey of primary forests, pioneer growths, rock savannah and plantations. The types of vegetation on these sampled sites and the number of samples for each plant species are summarized in Figure 1. We sampled the most common and accessible tank-bromeliad species at each site, Aechmea aquilega (AA), Aechmea mertensii (AM), Catopsis berteroniana (CB), Lutheria splendens (LS) and Vriesea pleiosticha (VP). These bromeliads belong to the subfamilies Bromelioideae (AA and AM) and Tillandsioideae (CB, LS, and VP). Aechmea mertensii (AM) bromeliads rooted on well-developed ant gardens inhabited by either the arboreal ants Camponotus femoratus or Neoponera goeldii (Corbara, 2020). As dispersal agents, ants determine the location of the seedlings and, because ant species have different preferences for light intensity, they indirectly influence the shape and structure of A. mertensii (Leroy et al., 2009). A. mertensii bore rosettes forming wide-open tanks with long leaves [ $C$. femoratus (AM-CF) preferably in shady areas], or the rosettes had an amphora shape with narrow tanks and shorter leaves [N. goeldii (AMNG), sunny areas; Leroy et al., 2009]. The AM-CF and AM-NG samples were therefore relevant to investigate the relative importance of plant species versus bromeliad habitat characteristics on APB microbiota structure and taxonomic composition. Catopsis berteroniana (CB) has been described as a protocarnivorous bromeliad that can rely on trapped prey, and may thus benefit from an additional nitrogen supply (Givnish et al., 1984). Both epiphytic bromeliads ( $<4 \mathrm{~m}$ aboveground) and those that had secondarily rooted on the ground were included in this analysis. We also analysed six samples from phytotelmata of Heliconia bracts $(\mathrm{H})$. These broad-leaved monocotyledons, having thick bracts that surround the flowers, were collected at the Kaw site (Figure 1), the only site where these container habitats were found close to bromeliad ones. Although limited, Heliconia sampling provides a preliminary evidence of the ubiquity of APB in phytotelmata. Furthermore, Heliconia samples enable to have an outgroup to the bromeliads.

\section{2 | Sampling procedure and environmental variables measured in tank bromeliads}

For both ethical (extensive sampling could destroy local populations) and legal reasons (the Nouragues Research Station is located in a nature reserve), we used a non-destructive sampling technique to extract the water contained into phytotelmata without harvesting, nor dismantling plants. All the water in the tanks of the different species of bromeliads and of Heliconia was collected using a 10-ml automatic pipette (Jocqué et al., 2010) and filtered through a 150-mm pore-size nylon screen (Brouard et al., 2012). Based on earlier studies of the bromeliad biota (Brouard et al., 2012; Dézerald et al., 2013; Lehours et al., 2016; Leroy et al., 2009, 2013, 2016), we selected a set of variables that are relevant predictors of community structure while minimizing multicollinearity among variables (Brandt et al., 2017; Louca et al., 2017). For individual bromeliads, we determined the intensity of the incident radiation (IR), the amount of leaf litter (FPOM) and the water volume of the tank (WV). These variables have also been shown to be significantly correlated with the APB functional group (Lehours et al., 2016; Louca et al., 2017).

The percentage of total incident radiation above bromeliads was calculated using hemispherical photographs and an image processing software (Gap Light Analyzer 2.0, Frazer et al., 1999), as described in Leroy et al. (2009). To characterize the size of the habitat, we emptied the wells by sucking the water out and recorded the corresponding volume of water ( $\mathrm{WV}, \mathrm{ml})$. The amount of fine particulate organic matter (FPOM; 1000-0.45 $\mu \mathrm{m}$ in size, Dézerald et al., 2013) was expressed as preserved volume ( $\mathrm{ml}$ after decantation into graduated test tubes, Paradise, 2004). Unpaired two-samples Wilcoxon tests (Mann-Whitney test) were performed to compare two independent groups of samples using stat_compare_means of the $\mathrm{R}$ package GGPUBR ( $v$ 0.2.5).

\subsection{Genomic DNA extraction and purification}

Microbial biomass was collected by filtration of 15 to $50 \mathrm{ml}$ water samples through polycarbonate membrane filters $(25 \mathrm{~mm}$ diameter, $0.2 \mu \mathrm{m}$ pore-size, GTTP, Millipore) and stored at $-20^{\circ} \mathrm{C}$ until DNA extraction. Genomic DNA was extracted according to the method described by Langenheder et al. (2003), with slight modifications. Filters were resuspended in $545 \mu$ of TE buffer $(\mathrm{pH} 8)$. Cells were lysed with lysozyme (Sigma, final concentration $20 \mathrm{mg}$ / $\mathrm{ml}$ ) for $30 \mathrm{~min}$ at $37^{\circ} \mathrm{C}$ and then incubated for $1 \mathrm{hr}$ at $37^{\circ} \mathrm{C}$ with sodium dodecyl sulphate (SDS, final concentration $0.5 \%$ ), proteinase $\mathrm{K}$ (Sigma, final concentration $0.1 \mathrm{mg} / \mathrm{ml}$ ) and RNaseA (Sigma, final concentration $0.8 \mu \mathrm{g} / \mathrm{ml}$ ). Cell debris, proteins and humic substances were removed by adding $100 \mu \mathrm{l}$ of a solution of cetyltrimethylammonium bromide (CTAB)/ $\mathrm{NaCl}(10 \%, w / v$, and $0.7 \mathrm{M}$, respectively) and $80 \mu \mathrm{l}$ of $\mathrm{NaCl} 5 \mathrm{M}$ for $10 \mathrm{~min}$ at $65^{\circ} \mathrm{C}$. CTABprotein/polysaccharide complexes were extracted with 1 volume of $\mathrm{CHCl}_{3}$ /isoamylalcohol (24:1) after centrifugation $\left(10,000 \mathrm{~g}, 4^{\circ} \mathrm{C}\right.$, $5 \mathrm{~min}$ ). Nucleic acids were precipitated with 0.6 volume of ice-cold isopropanol overnight, washed with $70 \%$ ethanol, air-dried and dissolved overnight in $50 \mathrm{ml}$ of $\mathrm{H}_{2} \mathrm{O}$. DNA was quantified using the Qubit $^{\circledR} 2.0$ fluorometer (Life Technologies) and stored at $-20^{\circ} \mathrm{C}$ until processing. 


\section{4 | pufM gene sequencing}

The diversity of APB was analysed using the polymorphism of the pufM gene encoding for one membrane spanning protein of the core of the photosynthetic reaction centre of photosystem II (Imhoff et al., 2018). The pufM genes were partially amplified using the primers pufM-557F (5'-CGCACCTGGACTGGAC-3') and pufM-750R (5'-CCCATGGTCCAGCGCCAGAA-3'; Achenbach et al., 2001). Each primer was modified with adapters to complement the Nextera XT index kit v2 set $D$ (Illumina). PCRs were performed in a $25 \mu$ reaction mixture containing $50 \mathrm{ng}$ of genomic DNA, Promega PCR buffer $1 \times$, $\mathrm{MgCl}_{2} 1 \mathrm{mM}$, dNTP $0.2 \mathrm{mM}$ of each, primers $0.5 \mathrm{mg} / \mathrm{ml}$ of each and $0.025 \mathrm{U}$ of GoTaqG2 Hot Start polymerase (Promega). Amplification proceeded under the following thermocycling conditions: $95^{\circ}$ for $5 \mathrm{~min}$ followed by $35 \mathrm{cycles}$ at $94^{\circ} \mathrm{C}$ for $30 \mathrm{~s}, 56^{\circ} \mathrm{C}$ for $30 \mathrm{~s}$ and $72^{\circ} \mathrm{C}$ for $30 \mathrm{~s}$ and a last step at $72^{\circ} \mathrm{C}$ for $10 \mathrm{~min}$. PCR products were purified with Agencourt AMPure XP beads (Beckman Coulter) and quantified on a Fragment Analyzer with High sensitivity fragment analysis kit (Agilent). The pufM amplicons from the 92 samples were indexed with the Nextera XT index kit v2 set D following the manufacturer protocol (Illumina). Indexed PCRs were purified with Agencourt AMPure XP beads (Beckman Coulter) and quantified on a Fragment Analyzer with High sensitivity fragment analysis kit (Agilent), normalized in equimolar amounts before pooling and sequencing on an Illumina MiSeq 300 bp paired-end platform (GATC Biotech). PhiX was spiked at $20 \%$ per lane. These raw sequence datasets have been submitted to the MG-RAST public database (http://metagenomi cs.anl.gov/) under ID number mgp95184.

\section{5 | Analysis of pufM sequences}

Raw Illumina paired-end reads were quality-trimmed using bbduk, and each read pair was merged into a single sequence with bbmerge (BBMap-38.69 suite, https://sourceforge.net/projects/ bbmap). Sequences containing any ambiguous base or holopolymer $>8$ bases were excluded using MOTHUR (Schloss et al., 2009), and only sequences of 200-275 bp lengths were retained. Next, chimeric sequences were removed using UCHIME (Edgar et al., 2011) with de-novo mode. To compare Operational Taxonomic Unit (OTU) abundances between samples, the overall dataset was first normalized by subsampling, taking into account the value of the smallest sample (39,985 sequences). These sequences were then clustered into OTUs using a $94 \%$ cut-off, which had previously proved to be optimal for grouping phylotypes related to the pufM gene (Lehours et al., 2010; Zeng et al., 2007). Dominant OTUs were defined as those representing $\geq 5 \%$ of a sample and abundant OTUs representing $\geq 1 \%$ within a sample (Ghiglione et al., 2012). OTUs with a representation $\geq 0.1 \%$ within a sample were considered as significant OTUs. Rarefaction curves of the pufM sequences were computed with the rarefaction.single command of MOTHUR, generating intrasample rarefaction curves using a re-sampling without replacement approach. The coverage was defined as $[1-(n / N)] \times 100$, where $n$ is the number of singleton clones and $N$ is the total number of sequences (Good, 1953). Visualization of pufM sequence sets, their sizes and intersections was performed with the $\mathrm{R}$ package based on the UpSet technique (Lex et al., 2014) and GGPLOT2 (Wickham, 2009).

\section{6 | Metrics used to analyse the structure of APB communities}

To deal with the compositional nature of data (Gloor et al., 2017), a centred log ratio transformation (CLR) was applied on the raw counts of OTU matrix abundances (Aitchison, 1982). The Aitchison formula was used to compute distances between pair of samples to perform further analyses of the beta-diversity (Aitchison et al., 2000). The distance matrix was generated using the significant OTUs (>0.1\%) with MOTHUR (Schloss et al., 2009). The hierarchical clustering (average linkage) and heatmap were subsequently performed using the PHEATMAP R package (Kolde \& Vilo, 2015). The optimal number of clusters was determined by calculating the silhouette coefficient using fviz_nbclust function from FACTOEXTRA R package (https://cran.rstudio.com/web/packages/ factoextra/factoextra.pdf) and PAM clustering was performed using pam function from CLUSTER R package (Mäechler et al., 2021). Analysis of similarities (ANOSIM) was used to test statistically the significance of theses clusters, using VEGAN R package with 9,999 permutations. MOTHUR was also used to compute the species richness $(S)$ and the species diversity estimated with the Shannon index ( $H^{\prime}$; Haegeman et al., 2013). The evenness (i.e. the distribution of individuals over species) was determined using the Pielou index ( $J$; S Smith \& Wilson, 1996).

\section{7 | Phylogenetic analysis performed using significant OTUs}

To avoid the pitfalls linked to the small size of the pufM amplicon ( 240 bp) and to achieve relevant phylogenetic assignments, we built the tree with full-length pufM sequences of established species or complete sequenced genomes (>780 complete sequences) and we accurately identified the reference organisms by species name and strain number (Imhoff et al., 2018). Complete sequences (hereafter, considered as 'References') were retrieved from KEGG (https://www.genome.jp/kegg/) and IMG (https://img.jgi.doe. gov) databases, using the pufM KO ID 'K08929' for query search. Furthermore, BLAST best hits from the NCBI NR database for the 89 significant OTUs (representing $90 \%$ of all sequences) were added to the dataset. A multiple alignment of the resulting 780 reference sequences was generated using MUSCLE (Edgar, 2004). A phylogenetic tree was build using Fasttree (Price et al., 2009), with the Jukes and Cantor model of DNA evolution (Jukes \& Cantor, 1969). The robustness of the inferred tree topologies was evaluated by bootstrap analysis (1,000 resamplings). Sequences of the 89 significant OTUs generated from this study were inserted to the multiple alignment of reference sequences using ARB (Ludwig et al., 2004), and added to the reference tree using ADD-BY-PARSIMONY algorithm 
as described previously (Lehours et al., 2010, 2018). Taxonomic affiliation of representative sequences for each significant OTU was defined according to their phylogenetic affiliations in the tree because APB populations affiliated to $\alpha$ - and $\beta$-Proteobacteria exhibit (a) a good phylogenetic and ecological coherence (Lehours et al., 2018) and (b) their pufLM and $16 \mathrm{~S}$ rDNA gene phylogenies are congruents (Imhoff et al., 2018). The taxonomy of sequences inserted within ambiguous taxonomic groups (composed of several APB genera) was defined as 'Unknown'. Phylogenetic tree display and annotations were performed with the iTOL software (Letunic \& Bork, 2016).

\section{8 | Inferences on the putative distribution of nitrogen fixation capability among APB in tank bromeliads}

Genomes of 'References', downloaded from KEGG and IMG databases, were checked for presence of the following nitrogen fixation genes: nifE, nifD, nifK, nifN, nifH and nifB. The functions of these genes are as follows: nifE, nitrogenase molybdenum-cofactor biosynthesis protein; nifD, nitrogenase molybdenum-iron protein subunit alpha; nifK, nitrogenase molybdenum-iron protein subunit beta; nifN, nitrogenase molybdenum-cofactor biosynthesis protein; nifH, nitrogenase reductase; nifB, FeMo cofactor biosynthesis protein (Dai et al., 2014). All of these genes are annotated as 'nitrogen fixation protein' corresponding to the KEGG ortholog groups K02587, K02586, K02591, $\mathrm{K} 02592, \mathrm{~K} 02588$ and K02585. As nifD and nifK are homologous to nifE and nifN, respectively (Fani, 2005), each of these pairs of proteins was considered as only one. Therefore, we searched in reference genomes for genes similar to these four nif genes (nifE or nifD, nifK or nifN, nifH, nifB) using BLASTp (evalue $<10^{-5}$ and bit-score $>50$; Altschul et al., 1990). An organism was considered to be a nitrogen fixer if at least three of the four nif genes were retrieved in its genome. OTUs affiliated with clades identified as nitrogen fixers were considered to have the potential to perform this metabolic activity. According to the last common ancestor, clades were identified in the phylogenetic tree and we confirmed such affiliation using BLAST scores. Only OTUs with more than $86 \%$ identity with pufM gene of a reference genome were annotated as 'nitrogen fixer' or 'not nitrogen fixer' Distant OTUs ( $<86 \%$ identity) were considered as 'unknown'. The cut-off value was chosen as isolates sharing pufLM gene sequence similarities of $86 \%$ coincide with $\geq 95 \%$ similarity with their corresponding $16 \mathrm{~S}$ rRNA gene (i.e. threshold recommended to classify bacteria at the genus level, Stackebrandt \& Goebel, 1994) and could therefore be reliably assigned to one defined group (Tank et al., 2009).

\section{3 | RESULTS}

\subsection{Habitat characteristics of tank bromeliads}

A total of 92 samples [86 from five tank-bromeliad species (Bromeliaceae) and 6 from one Heliconia species (Heliconiaceae),
Figure 1] were recovered in the understorey of primary forests, pioneer growths, rock savannah and plantations. For individual bromeliads, we determined the percentage of the incident radiation (IR), the amount of leaf litter (FPOM) and the water volume of the tank (WV). There were large and significant differences in IR, WV and FPOM among the different bromeliad species (Figure $1 \mathrm{C}-\mathrm{E}$ ). The two bromeliads growing in the rock savannah $[A$. aquilega $(\mathrm{AA})$ and $C$. berteroniana (CB)] showed the highest values for IR $(75.4 \pm 13.9 \%$ and $71.2 \pm 23.2 \%$, respectively, Figure $1 \mathrm{C}$ ). Although the understorey in primary forests site consistently received higher litter inputs than sun-exposed areas, the amount of FPOM inside the tank of bromeliads from primary forests at Petit-Saut [L. splendens (LS) and AA] was not necessarily higher than that from rock savannah at Nouragues site (CB and AA; Figure 1). Significant $\left(p<10^{-5}\right.$ ) differences in FPOM and $\mathrm{WV}$ proxies were observed between $A$. mertensii associated with the ants C. femoratus (AM-CF) or N. goeldii (AM-NG; Figure 1DE). A. aquilega and $V$. pleiosticha (VP) exhibited the highest $W V$ values $(794 \pm 772.9 \mathrm{ml}$ and $572.5 \pm 584.5 \mathrm{ml}$, respectively, Figure $1 \mathrm{E})$ with a huge variability between individual plants compared to the other tank-bromeliad species.

\section{2 | Description of sequence datasets}

High-throughput sequencing generated a total of 4,423,871 highquality pufM sequences, with an average 48,085 sequences per sample (minimum 39,985, maximum 49,454). After normalization of the dataset, curated sequences were clustered into 4,453 different operational taxonomic units (OTUs; 53-771 per sample). The coverage values (98.7\%-99.9\% per sample, Table S1) and near saturation of the rarefaction curves (data not shown) revealed that most of the current diversity was recovered from all samples. For all the samples analysed, approximately $25 \%, 75 \%$ and $90 \%$ of the relative abundance was due to three dominant OTUs (OTUs 0001-0003), 26 abundant OTUs (OTUs 0001-0026) and 89 significant OTUs (OTUs 0001-0088, OTU0091), respectively, indicating that few OTUs accounted for most of the APB abundance (Table S2).

\section{3 | Comparison of pufM datasets}

According to Silhouette values (Figure S1), the APB communities were optimally divided into five clusters in the hierarchical clustering analysis (HCA) performed using the 89 significant OTUs (Figure 2). Each plant species and each site consistently clustered together emphasizing that both the plant species $(r=0.8, p<0.0001$ from ANOSIM result) and the location ( $r=0.3, p<0.0001$ from ANOSIM result) had a significant effect on the assemblages of the APB (Figure 2). However, as demonstrated by ANOSIM statistics, differences in APB community structure were mainly driven by plant species demonstrating that the APB signatures were unique to each plant species. As no significant clustering was found at the plant subfamily or genus levels, the species level was the relevant taxonomic 


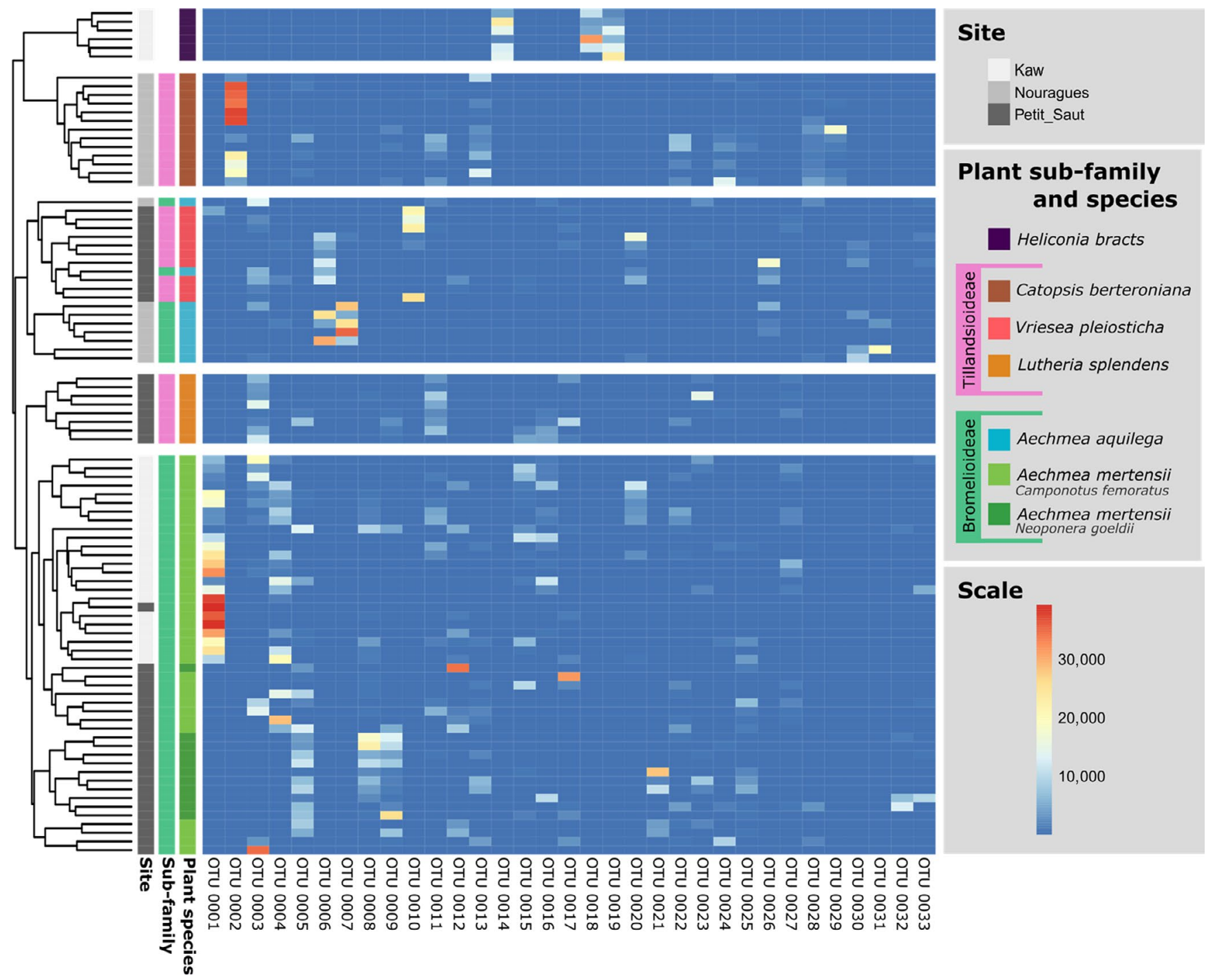

FIGURE 2 Hierarchical clustering analysis (HCA) according to OTU relative abundance (Aitchison distance) and heatmap showing OTU relative abundance and distribution across samples. The HCA and the heatmap were performed using the 89 significant OTUs but, for more clarity, only the 33 most abundant OTUs are shown. On the right $y$-axis, labels represent individual samples starting with plant species, followed by subfamily and site labels according to the colour-coded groups shown into the legend. OTUs are represented on the $x$-axis with corresponding relative abundances shown in the heatmap grid with increasing abundance from blue to red

rank for understanding the APB patterns in tank bromeliads. The impact of host plant species on APB assemblages was even more evident when considering conspecific hosts living in different locations, since geographical proximity may confound any species effect. For example, the 35 samples from A. mertensii associated with $C$. femoratus (AM-CF) clustered together $(r=0.4, p<0.0001$ from ANOSIM result) although 23 were collected at Petit-Saut and the others were collected at Kaw (Figure 2). In addition, analyses of APB patterns in A. mertensii tanks allowed to discriminate the effect of the tank habitat from that of the plant species. Despite the significant difference between AM-CF and AM-NG habitats at Petit-Saut (Figure 1CE), their APB communities grouped together (Figure 2). Besides, the APB community of $C$. berteroniana clustered separately from that of other bromeliad species ( $r=0.3, p<0.0001$; Figure 2$)$. The HCA also clearly showed that APB communities in Heliconia were distinct from those in tank bromeliads ( $r=0.4, p<0.0001$; Figure 2). The measurements of species richness $(S)$, diversity $\left(H^{\prime}\right)$ and evenness $\left(J^{\prime}\right)$ were also analysed to determine whether plant species had also an impact on these metrics. Overall, $S, H^{\prime}$ and $J^{\prime}$ were highly variable from one sample to another (Figure S2). The average lowest and highest values for species richness and diversity were observed for Heliconia bracts $\left(S=111, H^{\prime}=1.3\right)$, Lutheria splendens $\left(S=590, H^{\prime}=3.1\right)$ and Vriesea pleiosticha $\left(S=654, H^{\prime}=2.8\right.$; Figure S2; Table S1).

\section{4 | Taxonomic diversity of APB communities}

According to the high richness and low evenness of APB communities, phylogenetic analyses were performed using the 89 significant OTUs representing $90 \%$ of the sequences. Overall, the OTUs were 
distantly related to pufM sequences retrieved from environmental samples or from complete genomes, with only six OTUs showing more than $94 \%$ identity with publically available sequences (Table S2).

Consistent with previous data from 16S rDNA and pufM gene libraries derived from bromeliads (Lehours et al., 2016; Louca et al., 2017), all the significant OTUs belonged to purple nonsulphur bacteria and were distributed across the Alpha- and Betaclasses of the phylum Proteobacteria (Figures 3 and 4; Table S2). While this was also true for the APB community within Heliconia phytotelmata, analyses at lower taxonomic levels revealed several interesting patterns of APB. Considering all the datasets, by far the most abundant taxa belonged to the Alpha-proteobacteria ( $87 \%$ of total reads, $62 \%-96 \%$ per sample) whose sequences were assigned to orders Rhizobiales (60\%), Rhodospirillales (12\%), Sphingomonadales (8\%) and Rhodobacterales (7\%; Figures 3 and 4; Table S2). The order Burkholderiales within the Beta-proteobacteria accounted for a significant part of the APB community in the tanks of Heliconia bracts (27\%) and L. splendens (37\%), the two plant species growing on the ground.

The taxonomy of pufM sequences confirmed HCA analysis showing that $C$. berteroniana and Heliconia exhibited

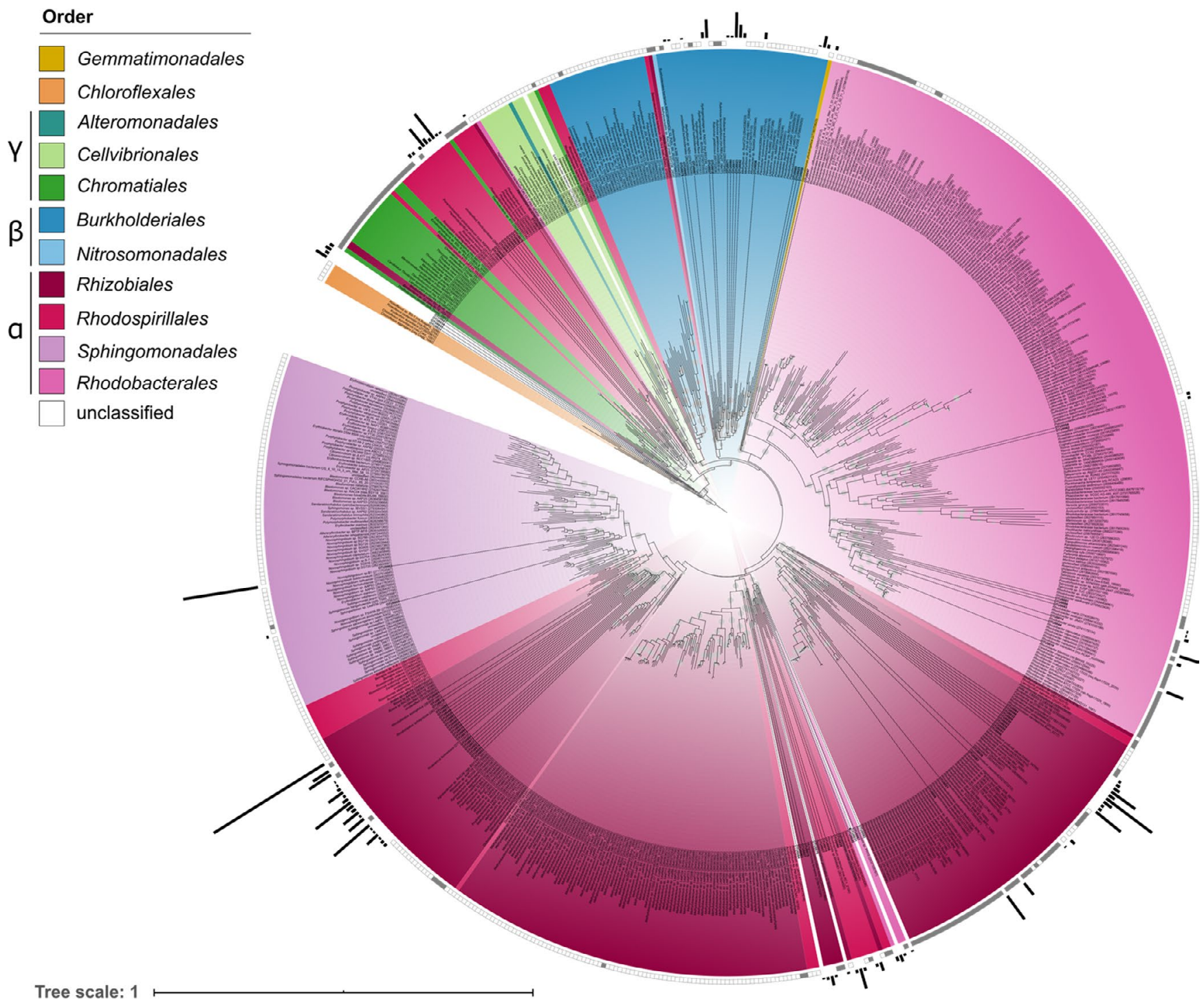

FIGURE 3 Overview on the phylogeny of pufM sequences from 780 sequences of types strains and complete genomes of anoxygenic phototrophic bacteria (i.e. references) together with the 89 significant OTUs (relative abundance $>0.1 \%$ ) generated in this study. References were checked for presence of nitrogen fixation genes, open square: nif genes were not detected, grey squares: nif genes were present. Sequences retrieved in this study are indicated as OTU0001 to OTU00089 and, for a better visualization, the dashed line linking the OTU number to the tree has been thickened. The black bar charts represent the relative frequencies of the corresponding OTU. The colour code identifies the belonging to different orders. The Rhizobiales, Rhodospirillales, Rhodobacterales and Sphingomonadales belong to the Alphaproteobacteria. The Burkholderiales and Nitrosomonadales are affiliated with the Beta-proteobacteria. The Chromatiales, Cellvibrionales and Alteromonadales belong to the Gamma-proteobacteria. Bootstrap values within a range of $80 \%-100 \%$ are represented with coloured circles of varying size 
FIGURE 4 Relative proportions of taxonomic groups (i.e. order ranks) identified $(A)$ in the water tanks of Aechmea mertensii associated with either Camponotus femoratus (AM-CF) or Neoponera goeldii (AM-NG) ants, (B) in the water tanks of each plant species
(A)
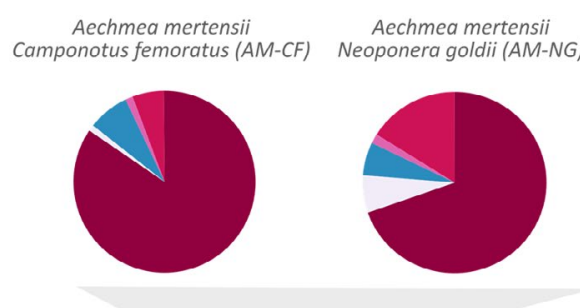

(B)

B) $\%$

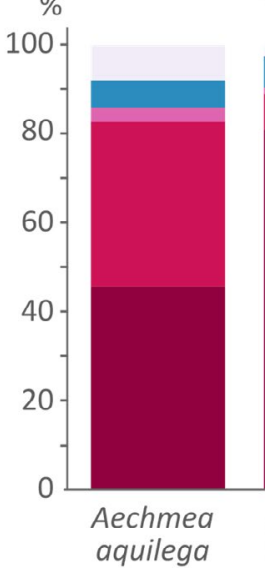

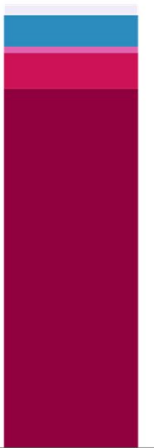

Aechmea mertensii

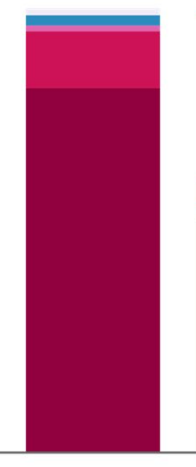

Vriesea pleiosticha

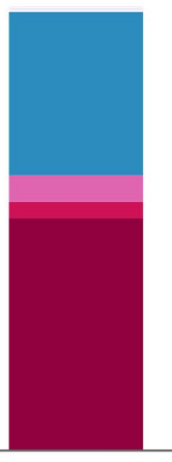

Lutheria splendens
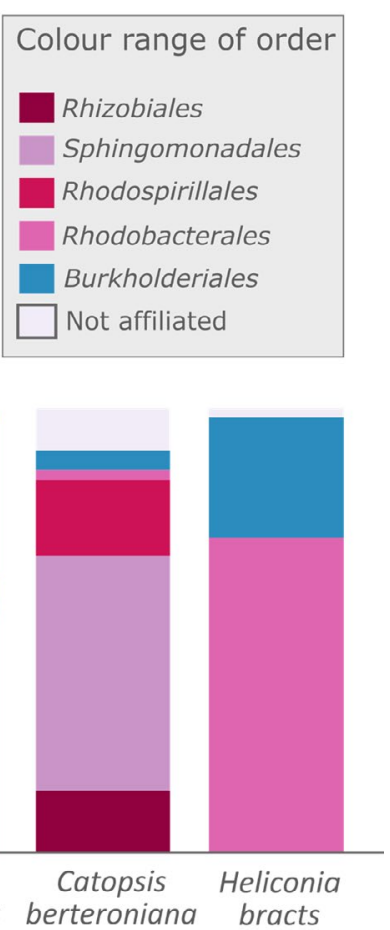

particular APB assemblages dominated by Sphingomonadales (53\%) and Rhodobacterales (71\%), respectively (Figures 3 and 4). In other tank bromeliads (AA, VP, LS and AM), the taxonomic composition of APB assemblages was remarkably similar with Rhizobiales ( 46\%$82 \%$ ) as the main component of the communities (Figures 3 and 4).

\subsection{Common taxa in tank bromeliads}

We examined the existence of a core APB microbiota (i.e. a set of OTUs shared among all bromeliads). The 5 bromeliad species shared 119 OTUs, accounting for only $2.9 \%$ of the bromeliad OTUs but, representing $91 \%$ of their abundance (Figure 5; Table S3). Among the core APB microbiota, the six abundant OTUs [OTU0001 (12\% of total OTU abundances), OTU0002 (7\%), OTU0003 (5\%), OTUs 0004 and 0005 (4\%), OTU0006 (3\%)] were also the most shared OTUs (Table S3). Considering the significant OTUs, most of the core APB in tank bromeliads (39 of the 89 significant OTUs, Figure 3; Table S3) was affiliated with the Rhizobiales. Unique OTUs were also observed with 714; 615; 555; 138 and 106 unique OTUs found in the water tanks of VP, AM, LS, CB and AA bromeliads, respectively (Figure 5). These unique OTUs were in low abundance, only containing between $0.003 \%$ and $0.03 \%$ of the total number of sequences, and can be considered as a variable APB microbiota. At the subfamily level of the bromeliads (Figure 1), the Tillandsioideae (including the genera Catopsis, Vriesea and Lutheria) and the Bromelioideae (represented by the genus Aechmea) had 18 and 42 common OTUs, respectively (Figure 5). In comparison, the APB community of Heliconia bracts comprised 82 OTUs out of the 216 OTUs identified in common with bromeliad species, representing $1.8 \%$ of all 4,453 OTUs but $85 \%$ of all OTUs abundances (Figure S3). The Venn diagrams performed for AM-CF and AM-NG confirmed the effect of plant species on APB assemblages (Figure 5B,C). AM-CF and AM-NG shared $>35 \%$ of their OTUs, a value much higher than those retrieved from bromeliad species (Figure 5). A similar pattern was observed for AM-CF sampled at Kaw and Petit-Saut (Figure 5). Finally, AM-CF and AM-NG shared $>98 \%$ of their OTU abundance (Figure 5).

\subsection{Deciphering the putative potential of APB for nitrogen fixation: Deductions from phylogenetic affiliations}

Reference genomes with nitrogen fixation genes were highlighted by a grey square on the phylogenetic tree (Figure 3). For details on the criteria used to do this discrimination, see material and method section. Among the 89 significant OTUs, 37 OTUs (61\% of the relative abundance of OTUs) were identified as representing potential nitrogen-fixing organisms. These 37 OTUs were affiliated with Rhizobiales and Rhodobacterales (Figure 3; Table S3). In particular, our analysis indicated that 2 of the 3 dominant OTUs (OTU0001 and OTU0003) may have the potential to fix nitrogen (Figure 3; Table S3). Among the Sphingomonadales and Burkholderiales, 8 OTUs were not affiliated with nitrogen-fixing clades, notably the dominant OTU0002 (Figure 3; Table S3). The remaining 44 OTUs were considered 'unknown' (Figure 3). With the exception of Catopsis berteroniana (only $14 \%$ of sequences affiliated to putative nitrogen fixers, Table S3), bromeliad-associated APB communities contained significant percentages $(41 \%-79 \%)$ of sequences affiliated with clades of organisms having nitrogen-fixing genes. 


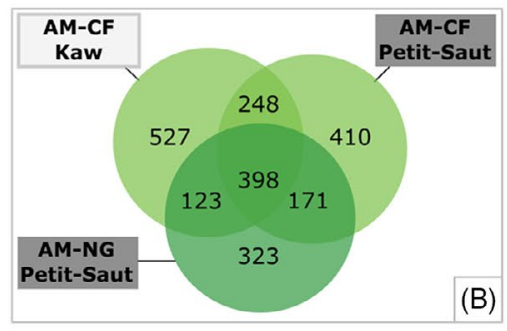

(A1) Total number of OTUs

(B)

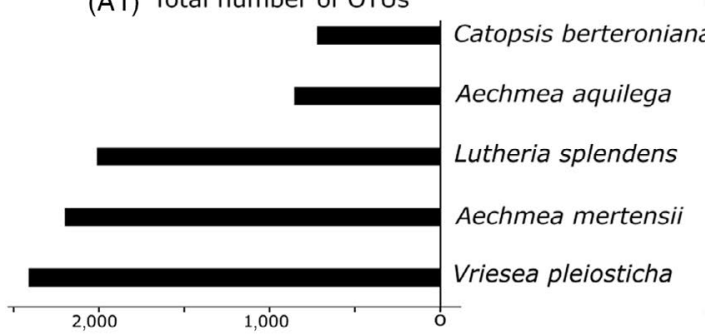

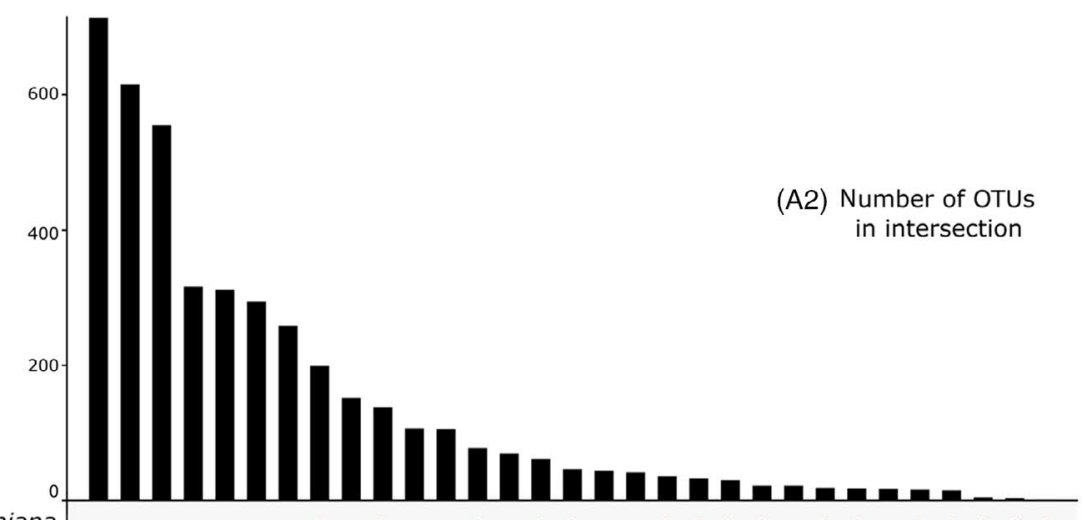

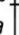
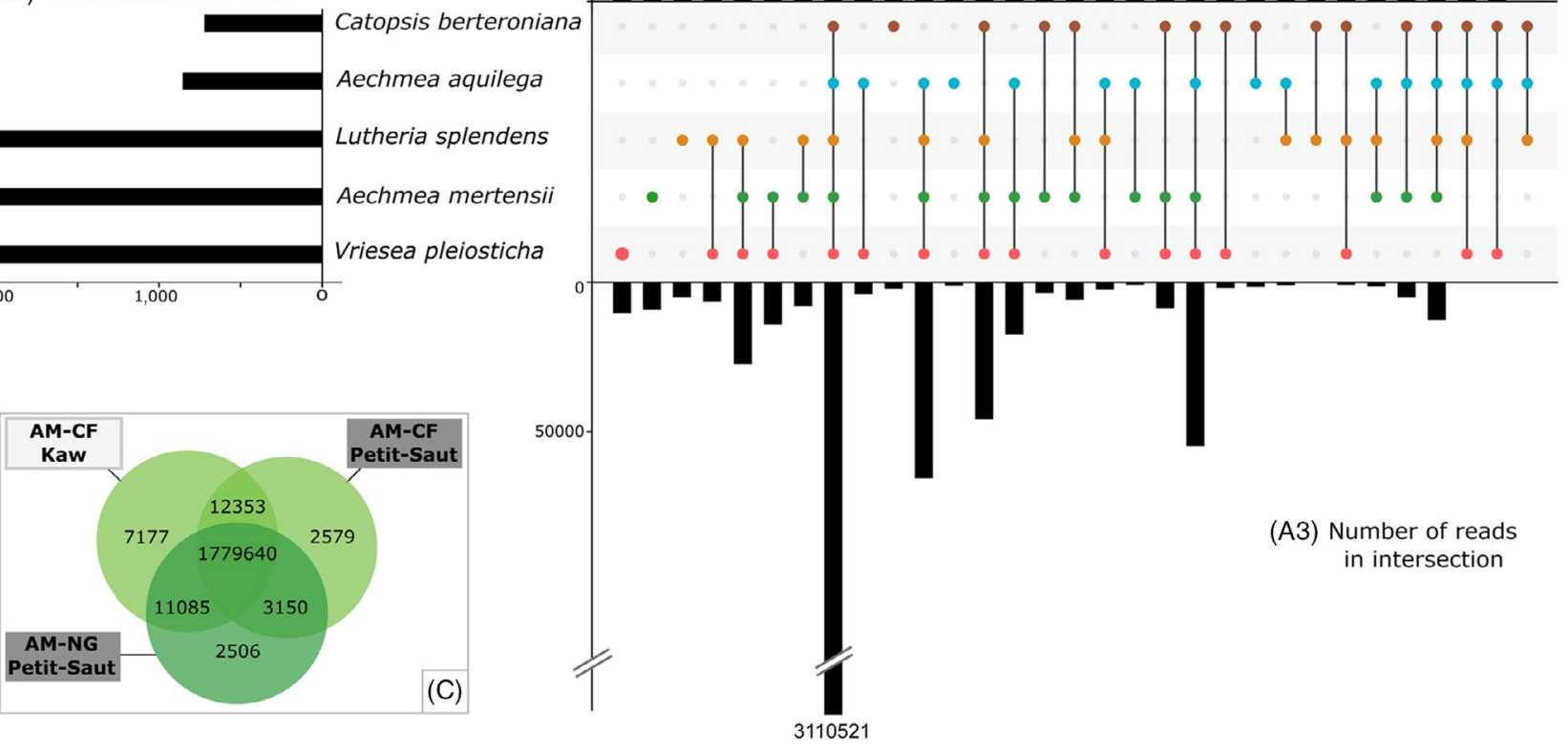

FIGURE 5 (A) An upset plot of bromeliad host species-specific core OTUs. (A1) Set metadata of each host species. Dark circles indicated samples with containing accessions and connecting bar indicated multiple overlapping samples, (A2) the number of unique and shared OTUs between datasets and (A3) the number of unique and shared pufM sequences between datasets (colours are similar to Figure 3). Venn diagrams showing the numbers of unique and shared (B) OTUs and (C) pufM sequences between Aechmea mertensii associated with either Camponotus femoratus (AM-CF) or Neoponera goeldii (AM-NG) ants sampled at Petit-Saut or at Kaw sites

\section{DISCUSSION}

For many years, research on symbiotic microbes and their relationship with plants focused on micro-organisms residing in the rhizosphere and to a lesser extent in the phyllosphere. These studies highlighted that the plant and its associated microbiota form an assemblage of species interacting with each other, that is often referred to as a 'holobiont' (Hassani et al., 2018; Zilber-Rosenberg \& Rosenberg, 2008). This concept notably sustains that plant genotype significantly contributes to shape the assembly rules of the microbiota associated with leaves and roots (e.g. Bulgarelli et al., 2013). Nevertheless, the question remains open for other plant habitats, such as phytotelmata, where there is still a lack of knowledge regarding whether plant influences microbial community establishment and how the associated microbiota members may promote plant fitness. In this study, we show that the bromeliad species significantly determine specific assemblages of APB, a prominent functional group of bacteria hosted into the water tanks of these plants. We also demonstrate that the host effects overwhelmed the environmental and stochastic factors. These findings suggest a codiversification between APB and tank bromeliads which may have led to functional reliances between APB microbiota and their host. In this vein, we hypothesize according to our genomic analyses, that APB may promote the bromeliad growth by provisioning essential nutrients like nitrogen.

\subsection{Bromeliad species shape a unique APB community in their tanks}

A fundamental principle of community ecology is that community structure and patterns of occurrence of species can be determined by niche processes (i.e. species traits) and/or by stochasticity (i.e. dispersal and demographic drift; Chase \& Leibold, 2003). However, investigations into processes controlling the microbial community composition in bromeliad water tanks failed to propose a consensual explanation for the full range of occurrence patterns. Taxonomic and 
functional compositions of microbial communities inhabiting tank bromeliads were found to be driven by the environmental characteristics of the bromeliads (Guimaraes-Souza et al., 2006; Louca et al., 2017; Marino et al., 2013). Niche-based processes have also been shown to be significant in shaping bacterial communities at the advanced stage of microbial succession during leaf-litter decomposition in tank bromeliad (Carrias et al., 2020). Other interpretations considered that each bromeliad plant represents a unique island with respect to its microbial community and reported a negligible association between bacterial species and habitat conditions suggesting that many bacteria may have similar fundamental niches, but do not occur everywhere because of limited dispersal (Carmo et al., 2014; Farjalla et al., 2012). In the present study, we found that the bromeliad species identity per se is a stronger determinant than habitat filtering or dispersal in controlling specific assembly rules for APB. Therefore, bromeliad species have not the same degree of effect on every group of microbial communities, affecting APB but not affecting all taxa. Moreover and interestingly, the fluorescence intensity of bacteriochlorophyll (i.e. a proxy of concentration) was not significantly different between bromeliad species (Lehours et al., 2016). This observation suggests that all bromeliad species offer a suitable habitat for anoxygenic phototrophy but select a characteristic suite of APB.

The importance of host species identity as driver of the structure of some groups in a community agrees with past studies of the phyllosphere and the rhizosphere of plants (e.g. Hassani et al., 2018; Laforest-Lapointe et al., 2016; Li et al., 2018; Vorholt, 2012) but, to our knowledge, has never been reported in phytotelm ecosystems. Our findings therefore support a co-diversification between APB and tank bromeliads, whereas deciphering if the bromeliad genotype shaped the APB diversity in the microbiota of the tank is challenging because host bromeliad species is inherently confounded with variations in habitat characteristics of the tank (Louca et al., 2017). To deeply investigate the influence of habitat in relation to plant species on the APB microbiota developing into the phytotelmata, the epiphytic bromeliad A. mertensii is an appropriate model with regard to its structural plasticity (Leroy et al., 2009). Although differences in phenology between AM-CF and AM-PG influence the geobiological characteristics in their tanks (Leroy et al., 2009), we observed a remarkably preserved APB structure and taxonomic composition between both bromeliad types as AM-CF and AM-NG from the Petit-Saut site clustered together. In addition, and because co-housing may confound any species effect, analyses of conspecific AM-CF hosts living separately, either at Petit-Saut or at Kaw sites, have shown that host species had a greater impact than distance on the composition of APB community. These results therefore confirmed that plant species was the main effect factor, the tank habitat and the location playing a subordinate role on the composition of APB. It is well known that plants can control their rhizospheric bacteria by secreting in the soil bioactive molecules (Reinhold-Hurek et al., 2015; Sasse et al., 2017). The root exudates generally include a complex mixture of sugars, carboxylic acids, amino acids that can stimulate bacterial growth, but also, secondary compounds, such as flavonoids that can act as signal to attract or repel bacteria or activate some bacterial biosynthesis pathways (Pascale et al., 2019). Similarly, bromeliads may secrete species-specific molecules in their phytotelmata to shape their associated APB microbiota.

\subsection{Key APB taxa have the potential for $\mathrm{N}_{2}$ fixation}

In this study, we had the opportunity to sample another class of phytotelmata, the water collected by bracts of Heliconia sp. growing at the Kaw site. This preliminary investigation enabled us to show that APB also occur in phytotelm ecosystems other than tank bromeliads. We observed large differences into the composition of the APB community between bromeliads and Heliconia. Explaining these marked differences would be speculative from these results due to the differential sampling effort and the lack of environmental data for Heliconia. But, this clustering of APB communities highlighted that in spite of a significant turn-over between species, bromeliads have a tightly associated APB community. This idea is reinforced by the observation that core OTU members (i.e. OTUs shared by all bromeliad species) were mainly the dominant ones and that in all bromeliad species, APB showed a taxonomic composition characterized by a particular combination of orders.

Consistent with previous findings, OTUs were affiliated with five orders (i.e. Rhodobacterales, Sphingomonadales, Rhizobiales, Rhodospirillales and Burkholderiales) among the Alpha- and Betaproteobacteria (Carrias et al., 2020; Lehours et al., 2016; Louca et al., 2017). Since these APB taxa are broadly distributed across bromeliad species and site locations, we assumed that they could be considered as key core microbial members of plant held water bodies. Moreover, these APB orders were also recorded as a significant component of the microbial communities inhabiting the phyllosphere (e.g. Atamna-Ismaeel et al., 2012; Knief et al., 2010; Laforest-Lapointe et al., 2016; Vokou et al., 2019) and therefore anoxygenic phototrophy may have a broad significance in the ecology of terrestrial plants.

Selective pressure acting on holobiont components has likely shaped plant-associated microbial communities and selected for host-adapted micro-organisms that impact plant fitness (Hassani et al., 2018). Many Rhizobiales are, for example, capable of fixing atmospheric nitrogen (Kembel et al., 2014; Madigan \& Jung, 2009) providing ammonium to plants for the synthesis of their amino acids (Lambais et al., 2017). This interaction generally occurs in the rhizosphere, but some studies have also shown that, in the stems of some legume plants, the efficiency in their $\mathrm{N}_{2}$ fixation was related to the photosynthetic activity of some Rhizobiales species (Giraud \& Fleischman, 2004; Giraud et al., 2000). In tank bromeliads, some APB taxa were also expected to contribute to the fitness of the plant through nitrogen fixation (Lehours et al., 2016), a significant and widespread metabolic activity in tank bromeliads of Neotropical rainforest (Carrias et al., 2020; Goffredi et al., 2015; Louca et al., 2016). Members of Rhizobiales and Rhodospirillales are notably known for their ability to fix atmospheric nitrogen (e.g. Carvalho et al., 2010; Madigan et al., 1984) and their significance in the bromeliad 
ecosystems is now documented (e.g. Carrias et al., 2020; Lehours et al., 2016; this study).

Phylogenetic conservatism of microbial traits likely arises from a microbial evolution proceeding mainly by vertical gene inheritance rather than horizontal gene transfer (Goberna \& Verdú, 2016; Kurland et al., 2003). We therefore considered that phylogeny reflected the molecular functions of APB as for Bacteria and Archaea (Langille et al., 2013; Martiny et al., 2013). Consequently, and despite a possible bias (Goberna \& Verdú, 2016), our current analysis revealed that up to $79 \%$ of OTUs belonged to APB clades that have the nitrogen fixation gene toolkit. We notably showed that two of the three dominant OTUs (OTUs 0001 and 0003) affiliated with the Rhizobiales were closely related to clades harbouring nitrogen fixation genes. This observation would not be due to chance alone as one of our recent analysis revealed that $\mathrm{N}$-fixing APB clades are enriched in tank bromeliads compared to other environments such as freshwater and marine environments (V. Darbot, F. Enault, A. Vergne, S. Roux, C. Bardot, I. Mary, H. Billard, E. Giraud, C. Jeanthon, \& A. C. Lehours, in prep.).

Collectively, these convergent observations support the hypothesis that bromeliads may benefit nutritionally from associations with free-living APB through the ability of these phototrophic bacteria to fix nitrogen. We acknowledge that this assumption is only based on indirect elements but the affiliation of the third dominant OTU (OTU0002) tends to accredit this hypothesis. APB populations within OTU0002 belonging to Sphingomonadales, repeatedly identified as one of the prevalent groups in the fluid of pitcher of carnivorous plants (e.g. Krieger \& Kourtev, 2012; Takeuchi et al., 2015), was only significantly detected in the tank of Catopsis berteroniana (CB) and, was not affiliated with a nitrogen-fixing clade. This observation is in line with our initial hypothesis because $\mathrm{CB}$ is a protocarnivore that derived nitrogen from insects they trap (Chase et al., 2009). Nevertheless, we acknowledge it is not clear whether nitrogen fixation is functional and active in the APB groups identified in tank bromeliads.

\section{3 | The bromeliad tanks, a favourable environment to promote phototrophic and nitrogen- fixing activity of $A P B$}

The APB require specific light and oxygen conditions to activate the expression of their photosynthetic genes. Indeed, it has been shown in some Bradyrhizobium or Rhodopseudomonas palustris strains, an unusual mechanism of regulation of photosystem formation by light, thanks to a bacteriophytochrome that senses light quality, and by oxygen, thanks to a redox sensitive transcriptional regulator named PpsR (Giraud et al., 2002; Jaubert et al., 2004). The Bromeliad tank may represent an ideal environment to promote the photosystem formation of APB. Indeed, most of the Bromeliad plants growth beneath the forest canopy, which absorbs preferentially blue and red light but transmits far-red light favouring the active far-red-light absorbing form (Pfr) of bacteriophytochrome. Furthermore, we can assume that at the bottom of the water column of the bromeliad tank, the oxygen tension drops, favouring the activation of photosynthetic genes by the PpsR regulator. In agreement, the very high content of $\mathrm{BChl}$ measured in water tank of bromeliads (Lehours et al., 2016) indicates that ABP should have a very high phototrophic activity. The oxygen lability of nitrogenase implies also a tight control of the expression of the nif genes by oxygen through other specific regulators that differ according to the bacterial species (Fisher, 1994). It can thus be assumed if the conditions in the water tank of bromeliad are favourable for the establishment of a photosynthetic activity, they should be also favourable, specifically in the case of APB that do not produce oxygen when photosystem works, for the establishment of a nitrogenase activity. Besides oxygen, the $\mathrm{N}_{2}$-fixation process could also be suppressed by the availability of reduced- $\mathrm{N}$ forms (e.g. Knapp, 2012; Xia et al., 2017). However, given that the decomposition of organic matter leads to oxygen depletion inside bromeliad tanks, promoting strong redox gradients (Guimaraes-Souza et al., 2006), nitrates may therefore become terminal electron acceptors for anaerobic microbial respiration (Canfield \& Thamdrup, 2009). The nitrogen loss via denitrification would thus do not inhibit the $\mathrm{N}_{2}$-fixation process. But and although there is a genetic potential for $\mathrm{N}_{2}$ fixation in the APB community, we acknowledge that further investigations are required to determine the impact of the nutritional richness of the tank on their nitrogenase activity.

\section{5 | CONCLUSIONS}

Our findings support the idea that plant host species is the main effect factor underlying the structural and taxonomic patterns of a metabolic group, the APB, in the phytotelm, a particular plant habitat. Nevertheless, we agree that such selection at the host level of specific members of the APB microbiota must be demonstrated, for example, by reciprocal transplantations of microbial communities from a bromeliad host species to recipients of another. Understanding the specific roles, adaptability and functions of APB microbiota of tank bromeliads is an exciting scientific perspective because the interplay of both partners is an intriguing aspect of possible mutualistic and coevolving interactions between the two existing forms of chlorophototrophy. Interactions between APB and plants are not only an exciting prospect in terms of Evolution but also in terms of Ecology. As various anoxygenic phototrophs were identified in the phyllosphere of terrestrial plants, APB might contribute more globally to plant health and growth (e.g. through $\mathrm{N}_{2}$ fixation) in natural and agricultural systems. In such a scenario, APB may have a potential plant probiotic power to confer a fitness advantage to the host. This scenario is nevertheless currently a research hypothesis that needs to be further studied, particularly concerning functional aspects of this interaction.

\section{ACKNOWLEDGEMENTS}

We are grateful to the staff members of the Laboratoire HYDRECO de Petit-Saut for their logistical help. A.V. was supported by 
a PhD fellowship from the French Ministry of Education and Research. Financial supports for this study were provided by the Fondation pour la Recherche sur la Biodiversite (Project MICBROME AAP-IN-2009-038), the Fédération des Recherches en Environnement (FR Environnement, UCA/CNRS FR 3467/ INRAE) and an Investissement d'Avenir grant (Labex CEBA, ref. ANR-10-LABX-25-01).

\section{AUTHORS' CONTRIBUTIONS}

A.-C.L. and I.M. conceived the ideas; A.-C.L., I.M., C.B. and A.-H.L.J. designed the methodology; R.C., B.C., J.-F.C. and C.L. collected the field data and samples; C.B. performed the biological experiments; V.D. and F.E. realized the bioinformatical analyses, A.-C.L., I.M., F.E., C.B., A.V. and V.D. analysed the data; A.-C.L., I.M., F.E., C.B., A.V., A.-H.L.J., V.D., R.C., B.C., J.-F.C. and C.L. interpreted the data; C.J. and E.G. revised critically the article for important intellectual content; A.-C.L. and A.V. led the writing of the manuscript. All authors contributed critically to the drafts and gave final approval for publication.

\section{PEER REVIEW}

The peer review history for this article is available at https://publons. com/publon/10.1111/1365-2745.13657.

\section{DATA AVAILABILITY STATEMENT}

Raw sequence datasets are deposited to the MG-RAST public database (http://metagenomics.anl.gov/) under ID number mgp95184.

\section{ORCID}

Jean-François Carrias (iD https://orcid.org/0000-0002-6201-1544

Bruno Corbara (iD https://orcid.org/0000-0003-4232-8234

Régis Céréghino iD https://orcid.org/0000-0003-3981-3159

Céline Leroy iD https://orcid.org/0000-0003-4859-8040

Anne-Catherine Lehours (iD https://orcid.org/0000-0001-9151-4389

\section{REFERENCES}

Achenbach, L. A., Carey, J., \& Madigan, M. T. (2001). Photosynthetic and phylogenetic primers for detection of anoxygenic phototrophs in natural environments. Applied and Environmental Microbiology, 67(7), 2922-2926. https://doi.org/10.1128/AEM.67.7.2922-2926. 2001

Agler, M. T., Ruhe, J., Kroll, S., Morhenn, C., Kim, S.-T., Weigel, D., \& Kemen, E. M. (2016). Microbial hub taxa link host and abiotic factors to plant microbiome variation. PLoS Biology, 14(1), e1002352.

Aitchison, J. (1982). The statistical analysis of compositional data. Journal of the Royal Statistical Society. Series B (Methodological), 44(2), 139177. https://doi.org/10.1111/j.2517-6161.1982.tb01195.x

Aitchison, J., Barceló-Vidal, C., Martín-Fernández, J. A., \& PawlowskyGlahn, V. (2000). Logratio analysis and compositional distance. Mathematical Geology, 32, 271-275.

Altschul, S. F., Gish, W., Miller, W., Myers, E. W., \& Lipman, D. J. (1990). Basic local alignment search tool. Journal of Molecular Biology, 215(3), 403-410. https://doi.org/10.1016/S0022-2836(05)80360 $-2$

Atamna-Ismaeel, N., Finkel, O., Glaser, F., von Mering, C., Vorholt, J. A., Koblížek, M., Belkin, S., \& Béjà, O. (2012). Bacterial anoxygenic photosynthesis on plant leaf surfaces. Environmental Microbiology Reports, 4, 209-216. https://doi.org/10.1111/j.1758-2229.2011. 00323.x

Benzing, D. H. (2000). Bromeliaceae: Profile of an adaptative radiation (p. 690). Cambridge University Press.

Benzing, D. H., \& Renfrow, A. (1974). The mineral nutrition of Bromeliaceae. Botanical Gazette, 135(4), 281-288. https://doi.org/ 10.1086/336762

Bongers, F., Charles-Dominique, P., Forget, P. M., \& Théry, M. (2001). Nouragues: Dynamics and plant-animal interactions in a Neotropical rainforest. Kluwer Academic Publishers.

Brandt, F. B., Martinson, G. O., \& Conrad, R. (2017). Bromeliad tanks are unique habitats for microbial communities involved in methane turnover. Plant and Soil, 410, 167-179. https://doi.org/10.1007/s1110 4-016-2988-9

Brouard, O., Céréghino, R., Corbara, B., Leroy, C., Pelozuelo, L., Dejean, A., \& Carrias, J.-F. (2012). Understorey environments influence functional diversity in tank-bromeliad ecosystems. Freshwater Biology, 57(4), 815-823. https://doi.org/10.1111/j.1365-2427.2012.02749.x

Brouard, O., Lejeune, A.-H., Leroy, C., Cereghino, R., Roux, O., Pelozuelo, O., Dejean, A., Corbara, B., \& Carrias, J.-F. (2011). Are algae relevant to the detritus-based food web in tank-bromeliads? PLoS ONE, 6(5), e20129. https://doi.org/10.1371/journal.pone.0020129

Bulgarelli, D., Schlaeppi, K., Spaepen, S., van Themaat, E. V. L., \& SchulzeLefert, P. (2013). Structure and functions of the bacterial microbiota of plants. Annual Review of Plant Biology, 64, 807-838. https://doi. org/10.1146/annurev-arplant-050312-120106

Butcher, D., \& Gouda, E. J. (2020). The new bromeliad taxon list. University Botanic Gardens. Retrieved from http://bromeliad.nl/taxonList/

Canfield, D. E., \& Thamdrup, B. (2009). Towards a consistent classification scheme for geochemical environments, or, why we wish the term 'suboxic' would go away. Geobiology, 7, 385-392. https://doi. org/10.1111/j.1472-4669.2009.00214.x

Carmo, F. L., Santos, H. F., Peixoto, R. S., Rosado, A. S., \& Araujo, F. V. (2014). Tank bromeliad water: Similar or distinct environments for research of bacterial bioactives? Brazilian Journal of Microbiology, 45, 185-192. https://doi.org/10.1590/S1517-83822014000100024

Carrias, J.-F., Gerphagnon, M., Rodríguez-Pérez, H., Borrel, G., Loiseau, C., Corbara, B., Céréghino, R., Mary, I., \& Leroy, C. (2020). Resource availability drives bacterial succession during leaf-litter decomposition in a bromeliad ecosystem. FEMS Microbiology Ecology, 96, fiaa045.

Carvalho, F. M., Souza, R. C., Barcellos, F. G., Hungria, M., \& Vasconcelos, A. T. R. (2010). Genomic and evolutionary comparisons of diazotrophic and pathogenic bacteria of the order Rhizobiales. BMC Microbiology, 10, 37. https://doi.org/10.1186/1471-2180-10-37

Céréghino, R., Leroy, C., Carrias, J. F., Pelozuelo, L., Ségura, C., Bosc, C., Dejean, A., \& Corbara, B. (2011). Ant-plant mutualisms promote functional diversity in phytotelm communities. Functional Ecology, 25, 954-963. https://doi.org/10.1111/j.1365-2435.2011.01863.x

Chase, J. M., \& Leibold, M. A. (2003). Ecological Niches: Linking classical and contemporary approaches. University of Chicago Press.

Chase, M. W., Christenhusz, M. J. M., Sanders, D., \& Fay, M. F. (2009). Murderous plants: Victorian Gothic, Darwin and modern insights into vegetable carnivory. Botanical Journal of the Linnean Society, 161, 329-356. https://doi.org/10.1111/j.1095-8339.2009.01014.x

Corbara, B. (2020). Ant Gardens. In C. Starr (Ed.), Encyclopedia of Social Insects. Springer.

Dai, Z., Guo, X., Yin, H., Liang, H., Cong, J., \& Liu, X. (2014). Identification of nitrogen-fixing genes and gene clusters from metagenomic library of acid mine drainage. PLoS ONE, 9, e87976. https://doi.org/10.1371/ journal.pone.0087976

Dézerald, O., Leroy, C., Corbara, B., Carrias, J.-F., Pélozuelo, L., Dejean, A., \& Céréghino, R. (2013). Food-web structure in relation to environmental gradients and predator-prey ratios in tank-bromeliad 
ecosystems. PLoS ONE, 8, e71735. https://doi.org/10.1371/journ al.pone.0071735

Douglas, A. E. (2014). Symbiosis as a general principle in eukaryotic evolution. Cold Spring Harbor Perspectives in Biology, 6(2), pii: a016113.

Edgar, R. C. (2004). MUSCLE: Multiple sequence alignment with high accuracy and high throughput. Nucleic Acids Research, 32, 1792-1797. https://doi.org/10.1093/nar/gkh340

Edgar, R. C., Haas, B. J., Clemente, J. C., Quince, C., \& Night, R. (2011). UCHIME improves sensitivity and speed of chimera detection. Bioinformatics, 27, 2194-2200. https://doi.org/10.1093/bioinforma tics/btr381

Endres, L., \& Mercier, H. (2003). Amino acid uptake and profile in bromeliads with different habits cultivated in vitro. Plant Physiology and Biochemistry, 41, 181-187. https://doi.org/10.1016/S0981-9428(02) 00025-6

Fani, R. (2005). On the origin and evolution of nif genes. In Y. P. Wang, M. Lin, Z. X. Tian, C. Elmerich, \& W. E. Newton (Eds.), Biological nitrogen fixation, sustainable agriculture and the environment. Current plant science and biotechnology in agriculture (Vol. 41). Springer.

Farjalla, V. F., Srivastava, D. S., Marino, N. A. C., Azevedo, F. D., Dib, V., Lopes, P. M., Rosado, A. S., Bozelli, R. L., \& Esteves, F. A. (2012). Ecological determinism increases with organism size. Ecology, 93, 1752-1759. https://doi.org/10.1890/11-1144.1

Fauteux, I., Cottrell, M. T., Kirchman, D. I., Borrego, C. M., Garcia-Chaves, M. C., \& del Giorgio, P. A. (2015). Patterns in abundance, cell size and pigment content of aerobic anoxygenic phototrophic bacteria along environmental gradients in northern lakes. PLoS ONE, 10, e0124035. https://doi.org/10.1371/journal.pone.0124035

Fischer, H. M. (1994). Genetic regulation of nitrogen fixation in rhizobia. Microbiological Reviews, 58, 352-386. https://doi.org/10.1128/ MR.58.3.352-386.1994

Frazer, G. W., Canham, C. D., \& Lertzman, K. P. (1999). Gap light analyzer (GLA) 2.0: Imaging software to extract canopy structure and gap light transmission indices from true-colour fisheye photographs: Users manual and program documentation. Simon Fraser University; Institute of Ecosystems Studies.

Ghiglione, J. F., Galand, P. E., Pommier, T., Pedrós-Alió, C., Maas, E. W. Bakker, K., Bertilson, S., Kirchman, D. L., Lovejoy, C., Yager, P. L., \& Murray, A. E. (2012). Pole-to-pole biogeography of surface and deep marine bacterial communities. Proceedings of the National Academy of Sciences of the United States of America, 109, 17633-17638. https:// doi.org/10.1073/pnas.1208160109

Giraud, E., Fardoux, J., Fourrier, N., Hannibal, L., Genty, B., Bouyer, P., Dreyfus, B., \& Verméglio, A. (2002). Bacteriophytochrome controls photosystem synthesis in anoxygenic bacteria. Nature, 417, 202-205. https://doi.org/10.1038/417202a

Giraud, E., \& Fleischman, D. (2004). Nitrogen-fixing symbiosis between photosynthetic bacteria and legumes. Photosynthesis Research, 82, 115-130. https://doi.org/10.1007/s11120-004-1768-1

Giraud, E., Hannibal, L., Fardoux, J., Verméglio, A., \& Dreyfus, B. (2000). Effects of Bradyrhizobium photosynthesis on stem nodulation of Aeschynomene sensitiva. Proceedings of the National Academy of Sciences of the United States of America, 97, 14795-14800.

Givnish, T. J., Burkhardt, E. L., Happel, R. E., \& Weintraub, J. D. (1984). Carnivory in the bromeliad Brocchinia reducta, with a cost/benefit model for the general restriction of carnivorous plants to sunny, moist, nutrient-poor habitats. The American Naturalist, 124, 479-497. https://doi.org/10.1086/284289

Gloor, G. B., Macklaim, J. M., Pawlowsky-Glahn, V., \& Egozcue, J. J. (2017). Microbiome datasets are compositional: And this is not optional. Frontiers in Microbiology, 8, 2224.

Goberna, M., \& Verdú, M. (2016). Predicting microbial traits with phylogenies. ISME Journal, 10, 959-967. https://doi.org/10.1038/ismej. 2015.171
Goericke, R. (2002). Bacteriochlorophyll a in the ocean: Is anoxygenic bacterial photosynthesis important? Limnology and Oceanography, 47 , 290-295.

Goffredi, S. K., Jang, G. E., \& Haroon, M. F. (2015). Transcriptomics in the tropics: Total RNA-based profiling of Costa Rican bromeliadassociated communities. Computational and Structural Biotechnology Journal, 13, 18-23. https://doi.org/10.1016/j.csbj.2014.12.001

Good, I. J. (1953). On the population frequency of species and the estimation of population parameters. Biometrika, 40, 237-264.

Guimaraes-Souza, B. A., Mendes, G. B., Bento, I., Marotta, H., Santoro, A. L., Esteves, F. A., Pinho, L., Farjalla, V. F., \& Enrich-prast, A. (2006). Limnological parameters in the water accumulated in tropical bromeliads. Acta Limnologica Brasiliensa, 18, 47-53.

Haegeman, B., Hamelin, J., Moriarty, J., Neal, P., Dushoff, J., \& Weitz, J. S. (2013). Robust estimation of microbial diversity in theory and in practice. The ISME Journal, 7, 1092-1101. https://doi.org/10.1038/ ismej.2013.10

Hassani, M. A., Durán, P., \& Hacquard, S. (2018). Microbial interactions within the plant holobiont. Microbiome, 6, 58. https://doi.org/10.1186/ s40168-018-0445-0

Imhoff, J. F. (2006). The family Ectothiorhodospiraceae. In M. Dworkin, S. Falkow, E. Rosenberg, K.-H. Schleifer, \& E. Stackebrandt (Eds.), The prokaryotes (3rd ed., pp. 874-886). Springer.

Imhoff, J. F., Rahn, T., Künzel, S., \& Neulinger, S. C. (2018). Photosynthesis is widely distributed among proteobacteria as demonstrated by the phylogeny of PufLM reaction center Proteins. Frontiers in Microbiology, 8, 2679. https://doi.org/10.3389/fmicb.2017.02679

Jaubert, M., Zappa, S., Fardoux, J., Adriano, J. M., Hannibal, L., Elsen, S., Lavergne, J., Verméglio, A., Giraud, E., \& Pignol, D. (2004). Light and redox control of photosynthesis gene expression in Bradyrhizobium: Dual roles of two PpsR. The Journal of Biological Chemistry, 279(43), 44407-44416. https://doi.org/10.1074/jbc. M408039200

Jocqué, M., Vanschoenwinkel, B., \& Brendonck, L. (2010). Freshwater rock pools: A review of habitat characteristics, faunal diversity and conservation value. Freshwater Biology, 55, 1587-1602. https://doi. org/10.1111/j.1365-2427.2010.02402.x

Jukes, T. H., \& Cantor, C. R. (1969). Evolution of protein molecules. In H N. Munro (Ed.), Mammalian protein metabolism (Vol. 3, pp. 21-132). Academic Press.

Kembel, S. W., O'Connor, T. K., Arnold, H. K., Hubbell, S. P., Wright, S. J., \& Green, J. L. (2014). Relationships between phyllosphere bacterial communities and plant functional traits in a neotropical forest. Proceedings of the National Academy of Sciences of the United States of America, 111, 13715-13720. https://doi.org/10.1073/pnas.12160 57111

Kitching, R. L. (2001). Food webs in phytotelmata: 'bottom-up' and 'top-down' explanations for community structure. Annual Review of Entomology, 46, 729-760.

Knapp, A. N. (2012). The sensitivity of marine N(2) fixation to dissolved inorganic nitrogen. Frontiers in Microbiology, 3, 374. https://doi. org/10.3389/fmicb.2012.00374

Knief, C., Ramette, A., Frances, L., Alonso-Blanco, C., \& Vorholt, J. A. (2010). Site and plant species are important determinants of the Methylobacterium community composition in the plant phyllosphere. The ISME Journal, 4, 719-728. https://doi.org/10.1038/ismej.2010.9

Koblížek, M. (2015). Ecology of aerobic anoxygenic phototrophs in aquatic environments. FEMS Microbiology Ecology, 39, 854-870.

Kolde, R., \& Vilo, J. (2015). GOsummaries: An R package for visual functional annotation of experimental data. F1000Research, 4, 574. https://doi.org/10.12688/f1000research.6925.1

Krieger, J. R., \& Kourtev, P. S. (2012). Bacterial diversity in three distinct sub-habitats within the pitchers of the northern pitcher plant, Sarracenia purpurea. FEMS Microbiology Ecology, 79(3), 555-567. https://doi.org/10.1111/j.1574-6941.2011.01240.x 
Kurland, C. G., Canback, B., \& Berg, O. G. (2003). Horizontal gene transfer: A critical view. Proceedings of the National Academy of Sciences of the United States of America, 100(17), 9658-9662. https://doi. org/10.1073/pnas.1632870100

Laforest-Lapointe, I., Messier, C., \& Kembel, S. W. (2016). Tree phyllosphere bacterial communities: Exploring the magnitude of intra- and inter-individual variation among host species. PeerJ, 4, e2367-e2318. https://doi.org/10.7717/peerj.2367

Lambais, M. R., Barrera, S. E., Santos, E. C., Crowley, D. E., \& Jumpponen, A. (2017). Phyllosphere metaproteomes of trees from the Brazilian Atlantic forest show high levels of functional redundancy. Microbial Ecology, 73, 123-134. https://doi.org/10.1007/ s00248-016-0878-6

Langenheder, S., Kisand, V., Wikner, J., \& Tranvik, L. J. (2003). Salinity as a structuring factor for the composition and performance of bacterioplankton degrading riverine DOC. FEMS Microbiology Ecology, 45, 189-202. https://doi.org/10.1016/S0168-6496(03)00149-1

Langille, M. G. I., Zaneveld, J., Caporaso, J. G., McDonald, D., Knights, D., Reyes, J. A., Clemente, J. C., Burkepile, D. E., Vega Thurber, R. L., Knight, R., Beiko, R. G., \& Huttenhower, C. (2013). Predictive functional profiling of microbial communities using $16 \mathrm{~S}$ rRNA marker gene sequences. Nature Biotechnology, 31(9), 814-821. https://doi. org/10.1038/nbt. 2676

Lehours, A.-C., Cottrell, M. T., Dahan, O., Kirchman, D. L., \& Jeanthon, C. (2010). Summer distribution and diversity of aerobic anoxygenic phototrophic bacteria in the Mediterranean Sea in relation to environmental variables. FEMS Microbiology Ecology, 74, 397-409. https://doi.org/10.1111/j.1574-6941.2010.00954.x

Lehours, A.-C., Enault, F., Boeuf, D., \& Jeanthon, C. (2018). Biogeographic patterns of aerobic anoxygenic phototrophic bacteria reveal an ecological consistency of phylogenetic clades in different oceanic biomes. Scientific Reports, 8, 4105. https://doi.org/10.1038/s4159 8-018-22413-7

Lehours, A.-C., Lejeune, A.-H., Aguer, J.-P., Céréghino, R., Corbara, B., Kéraval, B., Leroy, C., Perrière, F., Jeanthon, C., \& Carrias, J.-F. (2016). Unexpectedly high bacteriochlorophyll a concentrations in Neotropical tank bromeliads. Environmental Microbiology Reports, 8 , 689-698.

Leroy, C., Carrias, J.-F., Céréghino, R., \& Corbara, B. (2016). The contribution of microorganisms and metazoans to mineral nutrition in bromeliads. Journal of Plant Ecology, 9, 241-255. https://doi.org/10.1093/ jpe/rtv052

Leroy, C., Carrias, J.-F., Corbara, B., Pélozuelo, L., Dézerald, O., Brouard, O., Dejean, A., \& Céréghino, R. (2013). Mutualistic ants contribute to tank-bromeliad nutrition. Annals of Botany, 112, 919-926. https://doi. org/10.1093/aob/mct147

Leroy, C., Corbara, B., Dejean, A., \& Céréghino, R. (2009). Ants mediate foliar structure and nitrogen acquisition in a tank-bromeliad. New Phytologist, 183, 1124-1133. https://doi.org/10.1111/j.1469-8137. 2009.02891.x

Letunic, I., \& Bork, P. (2016). Interactive tree of life (iTOL) v3: An online tool for the display and annotation of phylogenetic and other trees. Nucleic Acids Research, 44, 242-245. https://doi.org/10.1093/nar/ gkw290

Lex, A., Gehlenborg, N., Strobelt, H., Vuillemot, R., \& Pfister, H. (2014). UpSet: Visualization of Intersecting Sets. IEEE Transactions on Visualization and Computer Graphics, 20, 1983-1992. https://doi. org/10.1109/TVCG.2014.2346248

Li, Y., Wu, X., Chen, T., Wang, W., Liu, G., Zhang, W., Li, S., Wang, M., Zhao, C., Zhou, H., \& Zhang, G. (2018). Plant phenotypic traits eventually shape its microbiota: A common garden test. Frontiers in Microbiology, 9, 2479. https://doi.org/10.3389/fmicb.2018.02479

Louca, S., Jacques, S. M. S., Pires, A. P. F., Leal, J. S., González, A. L., Doebeli, M., \& Farjalla, V. F. (2017). Functional structure of the bromeliad tank microbiome is strongly shaped by local geochemical conditions. Environmental Microbiology, 19(8), 3132-3151. https:// doi.org/10.1111/1462-2920.13788

Louca, S., Jacques, S. M. S., Pires, A. P. F., Leal, J. S., Srivastava, D. S., Parfrey, L. W., Farjalla, V. F., \& Doebeli, M. (2016). High taxonomic variability despite stable functional structure across microbial communities. Nature Ecology \& Evolution, 1(1), 15. https://doi. org/10.1038/s41559-016-0015

Ludwig, W., Strunk, O., Westram, R., Richter, L., Meier, H., Yadhukumar, A. B., Lai, T., Steppi, S., Jobb, G., Förster, W., Brettske, I., Gerber, S., Ginhart, A. W., Gross, O., Grumann, S., Hermann, S., Jost, R., König, A., Liss, T., ... Schleifer, K. H. (2004). ARB: A software environment for sequence data. Nucleic Acids Research, 32(4), 1363-1371. https:// doi.org/10.1093/nar/gkh293

Mäechler, M., Rousseeuw, P., Struyf, A., Hubert, M., \& Hornik, K. (2021). cluster: Cluster Analysis Basics and Extensions. R package version 2.1.1 - For new features, see the 'Changelog' file (in the package source). https://CRAN.R-project.org/package=cluster

Madigan, M. T., Cox, S. S., \& Stegeman, R. A. (1984). Nitrogen fixation and nitrogenase activities in members of the family Rhodospirillaceae. Journal of Bacteriology, 157, 73-78. https://doi.org/10.1128/JB.157. 1.73-78.1984

Madigan, M. T., \& Jung, D. O. (2009). An overview of purple bacteria: Systematics, physiology, and habitats (pp. 1-15). Springer Science.

Marino, N. A., Srivastava, D. S., \& Farjalla, V. F. (2013). Aquatic macroinvertebrate community composition in tank-bromeliads is determined by bromeliad species and its constrained characteristics. Insect Conservation and Diversity, 6(3), 372-380. https://doi.org/10.1111/ j.1752-4598.2012.00224.x

Martiny, A. C., Treseder, K., \& Pusch, G. (2013). Phylogenetic conservatism of functional traits in microorganisms. ISME Journal, 7(4), 830838. https://doi.org/10.1038/ismej.2012.160

Paradise, C. J. (2004). Relationship of water and leaf litter variability to insects inhabiting treeholes. Journal of the North American Benthological Society, 23, 793-805.

Partida-Martínez, L. P., \& Heil, M. (2011). The microbe-free plant: Fact or artifact? Frontiers in Plant Science, 2, 100. https://doi.org/10.3389/ fpls.2011.00100

Pascale, A., Proietti, S., Pantelides, I. S., \& Stringlis, I. A. (2019). Modulation of the root microbiome by plant molecules: The basis for targeted disease suppression and plant growth promotion. Frontiers Plant Sciences, 10, 1741. https://doi.org/10.3389/ fpls.2019.01741

Pittl, E., Innerebner, G., Wanek, W., \& Insam, H. (2010). Microbial communities of arboreal and ground soils in the Esquinas rainforest, Costa Rica. Plant and Soil, 329, 65-74. https://doi.org/10.1007/s1110 4-009-0134-7

Price, M. N., Dehal, P. S., \& Arkin, A. P. (2009). FastTree: Computing large minimum evolution trees with profiles instead of a distance matrix. Molecular Biology and Evolution, 26(7), 1641-1650. https://doi. org $/ 10.1093 / \mathrm{molbev} / \mathrm{msp} 077$

Reinhold-Hurek, B., Bunger, W., Burbano, C. S., Sabale, M., \& Hurek, T. (2015). Roots shaping their microbiome: Global hotspots for microbial activity. Annual Review of Phytopatholy, 53, 403-424. https://doi. org/10.1146/annurev-phyto-082712-102342

Romero, G. Q., Mazzafera, P., Vasconcellos-Neto, J., \& Trivelin, P. C. O. (2006). Bromeliad-living spiders improve host plant nutrition and growth. Ecology, 87, 803-808.

Sasse, J., Martinoia, E., \& Northen, T. (2017). Feed your friends: Do plant exudates shape the root microbiome? Trends Plant Science, 23, $25-$ 41. https://doi.org/10.1016/j.tplants.2017.09.003

Schloss, P. D., Westcott, S. L., Ryabin, T., Hall, J. R., Hartmann, M., Hollister, E. B., Lesniewski, R. A., Oakley, B. B., Parks, D. H., Robinson, C. J., Sahl, J. W., Stres, B., Thallinger, G. G., Van Horn, D. J., \& Weber, C. F. (2009). Introducing mothur: Open-source, platform- independent community-supported software for describing and comparing 
microbial communities. Applied and Environmental Microbiology, 75, 7537-7541. https://doi.org/10.1128/AEM.01541-09

Smith, B., \& Wilson, J. (1996). A consumer's guide to evenness indices. Oikos, 76(1), 70-82. https://doi.org/10.2307/3545749

Stackebrandt, E., \& Goebel, B. (1994). Taxonomic Note: A place for DNADNA reassociation and $16 \mathrm{~S}$ rRNA sequence analysis in the present species definition in bacteriology. International Journal of Systematic Bacteriology, 44, 846-849.

Takeuchi, Y., Chaffron, S., Salcher, M. M., Shimizu-Inatsugi, R., Kobayashi, M. J., Diway, B., von Mering, C., Pernthaler, J., \& Shimizu, K. K. (2015). Bacterial diversity and composition in the fluid of pitcher plants of the genus Nepenthes. Systematic and Applied Microbiology, 38, 330339. https://doi.org/10.1016/j.syapm.2015.05.006

Tank, M., Thiel, V., \& Imhoff, J. F. (2009). Phylogenetic relationship of phototrophic purple sulfur bacteria accordingto pufL and pufM genes. International Microbiology, 12, 175-185.

Vokou, D., Genitsaris, S., Karamanoli, K., Vareli, K., Zachari, M., Voggoli, D., Monokrousos, N., Halley, J. M., \& Sainis, I. (2019). Metagenomic characterization reveals pronounced seasonality in the diversity and structure of the phyllosphere bacterial community in a mediterranean ecosystem. Microorganisms, 7(11), 518. https://doi.org/ 10.3390/microorganisms7110518

Vorholt, J. A. (2012). Microbial life in the phyllosphere. Nature Reviews Microbiology, 10, 828-840. https://doi.org/10.1038/nrmicro2910

Whitham, T. G., Young, W. P., Martinsen, G. D., Gehring, C. A., Schweitzer, J. A., Shuster, S. M., Wimp, G. M., Fischer, D. G., Bailey, J. K., Lindroth, R. L., Woolbright, S., \& Kuske, C. R. (2003). Community and ecosystem genetics: A consequence of the extended phenotype. Ecology, 84, 559-573.
Wickham, H. (2009). ggplot2: Elegant graphics for data analysis. Springer-Verlag. Xia, X., Ma, C., Dong, S., Xu, Y., \& Gong, Z. (2017). Effects of nitrogen concentrations on nodulation and nitrogenase activity in dual root systems of soybean plants. Soil Science and Plant Nutrition, 63, 470482. https://doi.org/10.1080/00380768.2017.1370960

Zeng, Y. H., Chen, X. H., \& Jiao, N. Z. (2007). Genetic diversity assessment of anoxygenic photosynthetic bacteria by distance based grouping analysis of pufM sequences. Letters in Applied Microbiology, 45, 639-645. https://doi.org/10.1111/j.1472-765X. 2007.02247.x

Zilber-Rosenberg, I., \& Rosenberg, E. (2008). Role of microorganisms in the evolution of animals and plants: The hologenome theory of evolution. FEMS Microbiology Review, 32, 723-735. https://doi. org/10.1111/j.1574-6976.2008.00123.x

\section{SUPPORTING INFORMATION}

Additional supporting information may be found online in the Supporting Information section.

How to cite this article: Vergne A, Darbot V, Bardot C, et al. Assemblages of anoxygenic phototrophic bacteria in tank bromeliads exhibit a host-specific signature.

J Ecol. 2021;00:1-16. https://doi.org/10.1111/1365-

$\underline{2745.13657}$ 